\title{
LA MISIÓN DE LA UNIVERSIDAD EN LA EDAD MEDIA: SERVIR A LOS ALTOS ESTAMENTOS Y CONTRIBUIR AL DESARROLLO DE LAS CIUDADES
}

\author{
Joan Pedro Carañana ${ }^{1}$ \\ Universidad Complutense de Madrid
}

http://dx.doi.org/10.5209/rev_NOMA.2012.v34.n2.40743

\begin{abstract}
Resumen.- El artículo trata sobre la misión de la universidad medieval. En los primeros siglos de existencia de la universidad, su misión se orientó hacia la reproducción del poder de los altos estamentos y de las ciudades. El papado, la jerarquía eclesiástica, el sacro imperio romano, las monarquías y las fuerzas municipales ejercieron influencia sobre las universidades para conseguir apoyo en su lucha por la existencia y por el poder. El derecho fue una de las herramientas principales debido a que parte del conflicto entre el papado y el sacro imperio se dirimía en el ordenamiento jurídico. El primero promovió el derecho canónico en las universidades, mientras que el segundo favoreció el derecho romano. Además, las universidades tuvieron que participar en la lucha contra los movimientos heréticos y otros movimientos contestatarios. Desde la propia universidad se produjeron transgresiones de las misiones que los poderes dominantes asignaban institucionalmente a las universidades.
\end{abstract}

Palabras clave.- Universidad medieval, misión, mediación social, papado, sacro imperio, monarquía, ciudad, fe, herejía, movimientos sociales, Wyclif, goliardos.

Abstract.- This article is about the mission of the medieval university. In the first centuries of existence of the university, its mission was geared towards the reproduction of the power of the High Estates and of cities. The papacy, the church hierarchy, the Holy Roman Empire, monarchies and municipal forces influenced the universities to get support in their struggle for existence and power. Law was one of the main tools because the conflict between the papacy and the Holy Roman Empire was often settled in the legal system. The first promoted canon law at the universities, while the second favored Roman law. In addition, the universities had to participate in the fight against heretical movements and other anti-establishment movements. The institutional missions that the dominant powers assigned to universities were sometimes transgressed from the heart of university.

Keywords.- Medieval university, mission, social mediation, papacy, Holy Empire, monarchy, city, faith, heresy, social movements, Wyclif, goliards.

El objetivo del artículo es describir y analizar la misión de la universidad de la Baja Edad Media en lo que concierne al servicio que debía proporcionar a los altos estamentos y a las ciudades.

El marco teórico de la investigación está basado en la teoría de la Mediación social propuesta por Manuel Martín Serrano (1977. Reediciones en 1978, 1980, $1982,1984,1986$ y 2008$)^{2}$. Las instituciones mediadoras proponen modelos de orden para que los individuos y la sociedad interpreten la realidad y actúen de

\footnotetext{
${ }^{1}$ Doctorando FPU en el programa Comunicación, Cambio Social y Desarrollo, Departamento de Sociología IV, Facultad de Ciencias de la Información, Universidad Complutense de Madrid. Máster en Comunicación Social, UCM. joan.pedro@pdi.ucm.es.

${ }^{2}$ Vicente Baca (2012) proporciona un análisis sobre los modelos de articulación de las funciones sociales de la universidad, basado en la teoría de la mediación social.
} 
acuerdo con un conjunto de normas. Estos modelos y normas cambian con el tiempo. El punto de partida de la teoría es que hay una interdependencia entre el cambio social y la transformación de las instituciones mediadoras. En el caso de la universidad, esto significa que hay una relación de afectaciones mutuas entre el sistema social y el sistema universitario que produce cambios en ambos sistemas. Los modelos que la universidad promueve pueden analizarse a través de su misión. En el artículo, se identifican las misiones asignadas por distintos actores sociales que hacen referencia a lo que la universidad tiene que hacer y lo que no. Por tanto, las misiones consisten en representaciones sobre la universidad que la legitiman y la orientan para llevar a cabo unas determinadas actividades y objetivos.

En esta investigación se han identificado las misiones universitarias mediante un análisis de contenido de las representaciones públicas (bulas, documentos oficiales y otros escritos) proporcionadas por actores del periodo que se estudia. Se han analizado un total de treinta y ocho fuentes, veinticinco de ellas escritas en inglés, siete en latín, cinco en castellano y una en catalán. El modelo que se ha seguido para el análisis de contenido está basado en la etimología del término misión. Proviene del latín missionem (nom. missio), es decir el "acto de enviar" o de mittere, "enviar". Por tanto, la misión de la universidad se entiende como aquello que se espera que la universidad envíe (o no envíe), traslade, haga llegar, transmita, etc. a la sociedad. Implica una acción que trasciende el sistema universitario y que afecta a otros sistemas 0 instituciones sociales. Así pues, la misión siempre implica a un destinatario externo que se ve afectado por la universidad. En el trabajo se presentan las fuentes que muestran que:

Algún Actor Universitario puede llevar a cabo unas Acciones en orden a unos objetivos con consecuencias para algún Destinatario Externo.

Este modelo se ha empleado tanto para identificar y seleccionar la información pertinente de las fuentes que se han estudiado, como para establecer las misiones generales. El Actor Universitario puede ser institucional (la universidad, la facultad...), humano (los profesores, los estudiantes...) o metafórico (el conocimiento, el saber...). El Destinatario Externo puede cumplir las mismas características y, en muchos casos, aparecer solamente de manera implícita, por ejemplo cuando se refiere a la sociedad. La Acción puede ser de cualquier tipo y puede llevarse a cabo o no llevarse a cabo (la universidad no transmite $\mathrm{X}$ ). La aplicación de este esquema a las misiones generales que se desarrollan en este artículo queda de la siguiente manera: La misión de la universidad es 1. Servir a alguno de los altos estamentos y a las ciudades; 1.1. Servir al sacro imperio romano germánico y a las monarquías; 1.2. Servir al papado y a la jerarquía eclesiástica; 1.2.1. Apartar a los movimientos contrarios al orden establecido; 1.2.2. Propagar la fe y hacer proselitismo religioso; 1.2.3. Identificar y condenar las herejías; 1.3. Contribuir al desarrollo de las ciudades.

\section{Servir a alguno de los altos estamentos y contribuir al desarrollo de las ciudades.}


La universidad nace en la Europa bajo-medieval en un contexto de luchas por el poder entre el papado, el sacro imperio romano germánico, las monarquías y las ciudades. Como sugiere Rüegg (1992), si bien la función manifiesta de la universidad era velar por el bios theoretikos -la búsqueda desinteresada de la verdad (en este caso, de la verdad divina)-, la realidad social, o más concretamente, estos poderes sociales empujaron a la universidad a implicarse de lleno en asuntos mundanos que afectaban a la vida religiosa y política. Según el autor (ibíd., p. 14), los distintos actores sociales trataron de obtener apoyo del conocimiento universitario para su lucha por la existencia. Las universidades otorgaban prestigio y traían riqueza a los territorios y a sus líderes. Además, proporcionaban apoyo ideológico a los altos estamentos y favorecían la consolidación de su poder. Prosigue Rüegg (ibíd., p. 21) señalando que "[t]he social role of the medieval university consisted primarily of training for more rational forms of the exercise of authority in church, government, and society" [el rol social de la universidad medieval consistió principalmente en la formación para lograr una forma más racional del ejercicio de la autoridad en la iglesia, el gobierno y la sociedad].

Le Goff (1996, p. 12) va más allá y argumenta que los intelectuales universitarios se ajustan a la categoría de intelectuales orgánicos de Gramsci:

En una sociedad ideológicamente controlada de muy cerca por la Iglesia y políticamente cada vez más regida por una doble burocracia, laica y eclesiástica [...], los intelectuales de la Edad Media son ante todo intelectuales 'orgánicos', fieles servidores de la Iglesia y del Estado.

En el marco de las relaciones sociales que afectaban a la vida de las universidades medievales, éstas se implicaron progresivamente en asuntos políticos y de organización social. Los distintos poderes pugnaron por ponerlas a su servicio. Se produjeron algunos conflictos, aunque también se llegaron a consensos en los que se entendía que la universidad sería útil para los distintos actores sociales implicados. Por ejemplo, un acuerdo de 1344 entre el papa y el rey de Castilla hace referencia a los distintos poderes a los que la Universidad de Salamanca debía favorecer (Vidal y Díaz, 1869, pp. 25-26):

El estudio de Salamanca beneficia al Rey, al Reino, a la iglesia y a la villa de Salamanca

Desde las universidades se llevaron a cabo medidas de control social de las prácticas que contravenían a los estamentos privilegiados, en especial a la jerarquía eclesiástica. Un ejemplo es la condena de la fiesta de los locos o de los inocentes que el bajo clero celebraba en las iglesias, por parte de la Facultad de Teología de París en consonancia con las prohibiciones emitidas en los concilios eclesiásticos. Según la Catholic Encyclopedia (Thurston, 1909) la idea central de esta fiesta se correspondía con la de Saturnalia, la fiesta pagana de los esclavos en la antigua Roma, o sea, una breve revolución social en el que el poder, la dignidad y la impunidad pasa a manos de aquellos que ocupan posiciones subordinadas. Se trata de un carnaval en el que el bajo clero parodiaba a los altos cargos hasta puntos que se consideraban blasfemos y escandalosos, tal y como consta en el Concilio de Basilea, que prohibió 
finalmente su celebración en 1435 (cf. Tanner, 1990). La condena conciliar fue apoyada públicamente por la Universidad de París en un documento emitido por la Facultad de Teología (Thorndyke, 1975, pp. 343-346), del que se han obtenido los siguientes datos:

-The humble faculty of sacred theology of the dear university of Paris sends honor and the respect due to Christian piety.

-We abhor and detest the rite of a certain festivity which its celebrants call the Feast of Fools [...], in which priests and the clergy pollute themselves within and without, and foul the temple and churches of God.

-We declare what we feel in this matter, to the end that prelates may the more zealously and boldly expel this pestiferous rite from their subordinates.

-We beseech the celebrated fathers to listen and stretch every nerve in your power to dissipate and destroy this conglomeration of impiety.

-We conclude with the injunction that the continuation or abolition of this pestiferous rite depends on you prelates.

-We pray God the Father in his mercy, that he give you the spirit of strength against these diabolical ministers and all pestilent men.

[-La humilde facultad de sagrada teología de la querida Universidad de París envía el honor y el respeto debido a la piedad cristiana.

-Nosotros aborrecemos y detestamos el rito de cierta fiesta que sus celebrantes llaman la Fiesta de los Locos [...], en la que los sacerdotes y el clero se contaminan por dentro y por fuera e infectan el templo y las iglesias de Dios.

-Nosotros declaramos lo que sentimos en esta materia, a fin de que los prelados puedan, con el mayor celo y valentía, expulsar este rito pestilente de sus subordinados.

-Rogamos a los prelados que escuchéis y estiréis cada nervio en vuestro poder para disipar y destruir este conglomerado de impiedad.

-Llegamos a la conclusión con el mandato de que la continuación o la abolición de este rito pestilente depende de vosotros los prelados.

-Rogamos a Dios el Padre en su misericordia, que os de el espíritu de la fuerza contra estos ministros diabólicos y todos los hombres pestilentes.]

Las universidades ejercieron de consejo en diversos asuntos de relevancia social. Por ejemplo, en torno a las herejías. De acuerdo con Thorndyke (op. cit., p. 133), el 13 de octubre de 1307 los miembros de la orden de los Templarios en Francia fueron arrestados, sus propiedades confiscadas y enviados a los inquisidores para que respondiesen bajo tortura contra cargos de herejía, blasfemia e inmoralidad cometidos contra estos. El papa emprendió acciones en noviembre del mismo año, pero el monarca francés Felipe el Hermoso no estaba dispuesto a ceder poder al papa en su propio territorio y envió una carta a la Facultad de Teología para que le orientase sobre cómo proceder. Los teólogos llegaron a varias conclusiones. Además de avalar los cargos contra la orden, cabe destacar que establecen que la potestad de examinar, arrestar o castigar a los herejes no cae bajo la jurisdicción de los príncipes seculares, sino de la iglesia, excepto cuando amenace un peligro evidente y notorio y se haga con la intención de entregarlos lo antes posible a la iglesia. Con esta fórmula, los teólogos evitaban contrariar el poder del papado o malinterpretar la verdad de los testamentos y, al mismo tiempo, justificar la intervención del rey, al que 
transmitieron la idea de que los herejes debían ser castigados con inmediatez de acuerdo con su deseo sagrado. Según Thorndyke (ibíd.), el rey entregó la jurisdicción nominal a las autoridades eclesiásticas, pero mantuvo el control real. Es posible hacerse una idea más clara de las conclusiones de los teólogos resaltando algunas de las ideas calve (ibíd., pp. 133-136):

-The masters in theology at Paris with all subjection promptly and willingly ever offer grateful and devoted service to royal majesty.

-[We give our opinion on] how King Philip might proceed without infringement of another jurisdiction against certain subversors of the faith itself.

-We say that it seems to us that the authority of a secular judge does not extend to opening any prosecution in the matter of heresy against anyone not abandoned by the church, unless the church requests or has requested it, except when evident and notorious peril threatens, in which case under sure hope of ratification the secular power may arrest them with the intention of turning them over to the church so soon as opportunity shall offer.

-We say that, since, from confessions now made, strong suspicion exists against all of the order that they are heretics or accomplices [...], this should be suffice to condemn the order to the odium of particular persons or to inquiring against the entire order thus publicly sullied by so great crime

-We have concluded and written in unison, heartily wishing to follow the orders of the king and also the truth.

-We are prepared to expend much diligent study on those matters which shall please so great highness [his majesty].

-[We say] that may so great injury to the faith, of which you are the chief fist and defender, which is so scandalous and horrible to all Christian people, be speedily punished according to your holy desire.

-[Los maestros de teología en París, con toda sujeción, con prontitud y de buena gana siempre ofrecen servicio agradecido y devoto a la majestad real.

-(Damos nuestra opinión) sobre cómo el rey Felipe podría proceder sin infringir otra jurisdicción en contra de ciertos subversores de la misma fe.

-Decimos que nos parece que la autoridad de un juez secular no se extiende a la apertura de una acusación en materia de herejía contra alguien que no ha sido abandonado por la iglesia, a menos que la iglesia lo solicite o lo haya solicitado, excepto cuando amenace un peligro evidente y notorio, en cuyo caso, con la esperanza segura de ratificación, el poder secular puede detenerlos con la intención de entregarlos a la iglesia tan pronto como se dé la ocasión]

-Decimos que, puesto que existe, a partir de las confesiones hechas, fuerte sospecha contra toda la orden de que son herejes o cómplices [...], esto debería ser suficiente para condenar la orden al odio de las personas particulares o para indagar en contra de toda la orden de modo que sea públicamente mancillada por tan gran crimen.

-Hemos concluido y escrito al unísono, deseando de todo corazón seguir las órdenes del rey y también la verdad.

-Estamos dispuestos a dedicar mucho estudio diligente a los asuntos que plazcan a tan gran alteza (su majestad). 
-(Decimos) que tan gran lesión a la fe, de la cual usted es el principal puño y defensa, que es tan escandalosa y horrible para todo el pueblo cristiano, sea rápidamente castigada de acuerdo con su santo deseo.]

Uno de los episodios más trascendentes en el que la capacidad intelectual de la universidad se puso al servicio de los poderes dominantes fue la participación de la universidad de París, con Jean Gerson a la cabeza, en la resolución del Gran Cisma que dividió Europa. En este caso, intervino en un conflicto que implicaba directamente a la iglesia, al sacro imperio, a las monarquías y, en realidad, a toda la civilización cristiana. Como explican Cantoni y Yuchtman (2010, p. 12), desde 1309 a 1378 los papas residían en Aviñón en lugar de Roma (de ahí que el periodo recibiese el nombre de papado de Aviñón). En 1378 Gregorio XI movió la corte papal de vuelta a Roma y falleció poco después. La sucesión se concretó con la elección del papa Urbano $\mathrm{VI}$, quien permaneció en Roma, pero los cardenales franceses la consideraron inválida y eligieron en su lugar al (anti-papa) Clemente VII, quien mantuvo su corte en Aviñón. Se llegó así a una situación en la que coexistían dos papas rivales y en la que los señores seculares se dividieron entre los que juraron lealtad a uno o a otro. Salvo algunas excepciones, los territorios que se corresponden con Francia y con España fueron leales al papa de Aviñón, mientras que el sacro imperio y los estados italianos permanecieron leales a Roma. Poco después aparecería una tercera línea papal cuando el concilio de Pisa reclamó el papado para Alejandro V. La intervención de la Universidad de París se recogió en dos documentos de finales del XIV que muestran que ésta se alineo junto al anti-papa francés. Estas son las sentencias que se han obtenido de ellos (Janin, 2008, p. 88; Thatcher y McNeal, 1905, pp. 326-327; versión online en Halsall, 1996a):

-A commission of the University of Paris makes recommendations to the king on how to end the Great Schism (...).

-Masters and doctors of the University of Paris gave advice on which pope to recognize during the Great Schism to the king.

-Masters and doctors of the University of Paris recommended the recognition of pope Clement VII (instead of Urban VI).

[-Una comisión de la Universidad de París hace recomendaciones al rey sobre la manera de poner fin al Gran Cisma (...).

-Los maestros y doctores de la Universidad de París dieron consejo al rey sobre qué papa debía reconocer durante el Gran Cisma.

-Los maestros y doctores de la Universidad de París recomendaron el reconocimiento del papa Clemente VII (en lugar de Urbano VI)].

A pesar de que la iglesia (concretamente el papado) consiguió poner bajo su influencia a la mayor parte del sistema universitario, tuvo que competir con los otros poderes por su control. A partir del Gran Cisma y de la división de Europa se produce un debilitamiento del poder del papado que queda expuesto a constantes presiones de los poderes regionales en auge (Janin, op. cit., p. 88). En los epígrafes siguientes se muestran referencias del apoyo que las universidades brindaron al papado, al sacro imperio, a la monarquía y a la ciudad, así como algunos episodios de conflicto. Si bien los documentos 
provenientes de los representantes del poder establecido muestran su afán por controlar la universidad y ponerla a su servicio, los miembros de las universidades no siempre cedieron. A nivel institucional, las universidades debían estar al servicio de las élites sociales, pero también lograron mantener cierta autonomía y se implicaron en ideas y actividades que contravenían esta misión.

\subsection{Servir al sacro imperio romano germánico y a las monarquías}

Los emperadores entendieron que los centros de educación superior serían útiles para su imperio $\mathrm{y}$, consecuentemente, fundaron algunas universidades para ponerlas a su servicio. La universidad contribuiría a la estabilidad del orden social, proporcionaría salud económica, elevaría el prestigio del territorio y permitiría contar con un cuerpo experto que aconsejase o trabajase para el emperador. Para los emperadores era particularmente importante fortalecer el derecho romano o derecho civil puesto que se consideraba el núcleo de la organización y desempeño imperial. La batalla entre el imperio y el pontificado por el dominum mundi se libró, en buena medida, en torno al ordenamiento jurídico. Federico II afirmó que el trono imperial debía ser poderoso en razón tanto de la fuerza de la ley como de la fuerza de las armas (Nardi, 1992, p. 88). En el campo de la ley, el papado se centró en el derecho canónico, mientras que los emperadores recurrieron al derecho romano para fortalecer sus poderes fiscales y políticos (Rüegg, op. cit., p. 15).

Fue durante el reinado de Federico I Barbarroja, cuando el ideal imperial comenzó a desarrollarse con brío. Federico I tomó como modelo de emperador a Carlomagno y se consideró sucesor del antiguo imperio romano. Fundamentó su imperio en el derecho romano, en particular en el código de Justiniano o, como se conoció posteriormente, el Corpus iuris civilis. Barbaroja encontró ahí los argumentos racionales y legales para justificar sus ambiciones imperiales de supremacía respecto a los territorios y el poder del papado. A partir de los argumentos que proporcionaba el derecho, introdujo la calificación de Sacrum para referirse al imperio. Que el imperio fuese sagrado justificaba su existencia y poder sobre la base de que emanaban de la voluntad divina. El imperio constituiría así una forma de organización política de la humanidad de carácter natural y universal.

Un tiempo antes de ser reconocido oficialmente, el studium de Bolonia ya destacaba en el derecho romano. Pepo e Irnero fueron dos de los maestros más influyentes. Zanotti (1994, p. 18) explica que en el año 1158 Federico Barbaroja consultó a cuatro doctores formados con Irnero que demostraron al emperador que el derecho romano en el que se basaba el imperio era el único válido. Añade que el mismo año Federico reconoció oficialmente a la Universidad de Bolonia firmando su Carta Magna, la Authentica Habita. En ella, el emperador hizo patente su interés en que la universidad favoreciese los intereses del imperio (Ogg, 1908, pp. 341-3):

-It is by learning that the world is enlightened to the obedience of God and of us, his ministers. 
[-A través del aprendizaje el mundo se ilumina hacia la obediencia a Dios y a nosotros, sus ministros / pastores.]

Según Rüegg (op. cit., p. 14), esta formulación retórica delinea con precisión las expectativas duales del emperador: El simbolismo de la luz, tan común en la Edad Media, expresa la visión de que los estudios enriquecen el conocimiento y dan estabilidad al orden social. Nardi (op. cit., pp. 78-79) señala que mediante este decreto se extendían los privilegios del clero (privilegium fori) a los estudiantes seglares y se confirmaba una vieja norma imperial recogida por Justiniano, según la cual el obispo y los maestros tenían el derecho de juzgar a los estudiantes. Nardi añade que Federico I hizo que la Habita se insertase en el Código de Justiniano, lo cual refleja su deseo de revivir el derecho romano e incorporarlo al sistema legal del imperio. Su plan, continúa el autor, resultó conveniente para los maestros de Bolonia, quienes como intérpretes y profesores del derecho Justiniano, tenían interés en que fuese reconocido y aplicado de manera generalizada.

Zanotti (op. cit., p. 18) indica que la Universidad de Bolonia estuvo sometida a diversas tensiones por parte de los poderes que trataban de aprovechar su prestigio. A finales siglo XII, las comunas italianas vencieron al emperador y la universidad de Bolonia cayó bajo control de la ciudad que prohibió a los profesores enseñar fuera de sus límites. En el siglo XIII las rivalidades por dominar la universidad continuaron. El papa Honorio III concedió al archidiácono de la catedral de Bolonia la autoridad de conferir grados universitarios con validez universal. El emperador Federico II Hohenstaufen, al perder el control sobre esta universidad, decidió fundar la de Nápoles para ponerla al servicio de su imperio, tal y como consta en el documento fundacional de 1224 (Spagnuolo, 1998):

-The wise and knowledgeable (of the University of Naples) will serve divine justice.

-The wise and knowledgeable will become useful to us [the Emperor].

-The wise and knowledgeable will become useful for the administration of Justice and of the laws which we urge everyone to obey.

[-Los sabios y cultos (de la Universidad de Nápoles) servirán a la justicia divina. -Los sabios y cultos se convertirán en útiles para nosotros (el emperador).

-Los sabios y cultos se convertirán en útiles para la administración de la Justicia y de las leyes a las que urgimos a todos que obedezcan.]

Federico II entendía que la justicia divina guarda relación con el imperio, en particular con sus leyes. Las leyes del imperio provienen de la voluntad divina y el emperador es sólo un mediador encargado de aplicarlas en el mundo terrenal. El objetivo con el que del emperador funda la Universidad de Nápoles consistía en proporcionar la educación adecuada para formar expertos en derecho civil que ayudasen a lograr sus objetivos imperiales. Según Nardi (op. cit., p. 87-88), en un principio la intención del emperador era formar a la clase dirigente del reino de Sicilia. Sin embargo, los objetivos del emperador se volvieron más ambiciosos y pronto "aspired to nothing less tan creating a great 
intellectual élite to sustain the imperial throne with the instruments of law and the prestige of culture" ["aspiró nada menos que a crear una gran élite intelectual para sostener el trono imperial con los instrumentos del derecho y el prestigio de la cultura"] (ibíd., p. 88). Para ello, reunió en Nápoles una platilla de maestros eminentes, especialmente de juristas. El autor (ibíd., p. 87) indica que la diferencia principal entre la Universidad de Nápoles y el resto de universidades europeas era que los poderes eclesiásticos no tenían autoridad para reclutar a maestros, para otorgar la licentia docendi, es decir la autorización para poder enseñar, ni para ejercer poderes jurisdiccionales. De este modo, el emperador trató de apartar a la iglesia de la organización y gestión universitaria.

El comentario al decreto en el Internet Medieval Sourcebook (Spagnuolo, op. cit.) proporciona algunos datos sobre algunas de las relaciones que se desarrollaron entre el emperador, la Universidad de Nápoles, la de Bolonia y el papado. En estas relaciones la ley cumplía un papel relevante: Los estudiantes de Bolonia ridiculizaban la idea de la Universidad de Nápoles como un embrión de improbable desarrollo. Por su parte, Federico trató de concentrar forzosamente en Nápoles a todos los estudiosos del reino por la vía legal e intentó cerrar la Universidad de Bolonia. La comuna de Bolonia respondió con leyes que permitían la confiscación de bienes de los maestros y estudiantes que abandonasen la universidad. Federico advirtió a los regentes de Bolonia que estas leyes para evitar el éxodo de estudiosos eran illusiones y promulgó nuevas leyes prohibiendo a todos los estudiantes y maestros acudir a Bolonia, bajo pena de la pérdida de ciertos derechos fundamentales. También declaró nulas e inválidas todas las sentencias provenientes de Bolonia. Sin embargo, no tuvo éxito en cerrar la universidad. El papa se reconcilió con las autoridades locales y permitió la continuidad de la universidad bajo su auspicio.

Davis (2006, p. 410) argumenta que la fundación de una universidad imperial para formar a los futuros empleados y consejeros del imperio fue, en lo que respecta al occidente latino, "a startling innovation, since learning lay within the province of the Church, and the existing universities, such as Paris and Bologna, were ecclesiastical institutions for the training of churchmen" [una innovación extraordinaria, ya que la enseñanza era competencia de la Iglesia, y las universidades existentes, tales como París y Bolonia, eran instituciones eclesiásticas para la formación de los clérigos]. Según el autor, "Frederick's university was the first state university in Europe" [La universidad de Federico fue la primera universidad estatal en Europa] (Ibid.). Para Rüegg (op. cit., p. 18), la fundación de la Universidad de Nápoles y los esfuerzos del emperador por disolver la Universidad de Bolonia constituyen un caso extremo del vínculo que los monarcas y los emperadores trataron de establecer entre las universidades y su política territorial. Añade que el prototipo de universidad estatal de Federico II se colapsó tras cinco años, pero se convirtió en un modelo institucional generalizado sólo tres siglos más tarde. Más tarde, en 1355, el emperador Carlos IV dio a la Universidad de Perugia el status de universidad imperial.

También los reyes procuraron que su territorio se viese beneficiado por las universidades, sobre todo a partir del siglo XIII, cuando se produce un proceso 
de consolidación y centralización monárquica. Además de atraer riqueza y prestigio a los reinos, las universidades proporcionaban apoyo intelectual para la consolidación de las instituciones administrativas y gubernamentales que los monarcas necesitaban para sobreponerse a las fuerzas centrífugas, sobre todo a la aristocracia urbana y terrateniente (Rüegg, op. cit, p. 18). Por ello, los monarcas trataron poner a su servicio los conocimientos del gremio universitario y de vincular las universidades a su propia política territorial. Por ejemplo, en Castilla, Fernando III el Santo confirmó en 1243 que hubiese estudios en Salamanca porque, según consta en la carta, entendía que beneficiarían a su propio reino (Hernández-Vicente, 1994, p. 26; Vidal y Díaz, op. cit., p. 15):

-Las escuelas de Salamanca son en pro de myo rregno e de mi tierra.

Por su parte, el rey Alfonso X el Sabio destacó en el libro Las siete partidas, libro de gran importancia para la época donde definía el concepto de estudio general, que los sabios y, en particular, el derecho ayudan al bienestar y gestión de los reinos (si bien, complementariamente, también indica que los estudios son útiles a la iglesia). Dice así el monarca (López, 2008):

-Los sabios guían, protegen y aconsejan a los hombres, a las tierras y a los reinos.

-La ciencia de las leyes sirve, más que las otras ciencias, al mundo.

Esta tradición continuó en la realeza castellana a lo largo del periodo medieval. En 1401 el monarca Enrique III, el Doliente, también expresó públicamente que la universidad le era beneficiosa, cuando confirmó los privilegios de los estudiantes de la Universidad de Salamanca, según palabras del propio rey (Vidal y Díaz, op. cit., p. 36):

-En reconocimiento de los muchos é buenos, é muy leales servicios que ficisteis, é facedes a mi cada dia.

El papa Juan XXII también parecía compartir la idea de que las universidades y los intelectuales benefician a los reinos. A solicitud del rey Eduardo II de Inglaterra emitió la bula Inter singula en 1318 como confirmación de la Universidad de Cambridge exponiendo lo siguiente (original en latín en Fuller, Pochett y Wright, 1840, p. 80; traducción al inglés en In Rebus, s.f.):

-The wise are endowed towards the purpose of guiding nations and kingdoms and are intent upon the common progress of their subjects.

-The wise are concerned for the welfare of public interests.

-Learned men allow for the prosperity of nations.

-The wise advise the rulings of governors and kings.

[-Los sabios están dotados para el propósito de guiar a las naciones y a los reinos, y están decididos a promover el progreso común de sus súbditos.

-Los sabios se preocupan por el bienestar de los intereses públicos.

-Los hombres de saber permiten la prosperidad de las naciones.

-Los sabios aconsejan el gobierno de los gobernadores y los reyes.] 
En 1367, estando la ciudad francesa de Cahors bajo dominio inglés, el príncipe de Gales Eduardo de Woodstock, más tarde conocido como el Príncipe Negro, confirmaba los privilegios de la universidad destacando el valor que los maestros de leyes tenían para la corona. El príncipe escribió (Compayré, 2010, pp. 19-20):

-It is benefiting to crown with all the gifts of our munificence those who teach how to distinguish the just from the unjust.

[-Es beneficioso para la corona, con todos los dones de nuestra generosidad, aquellos que enseñan a distinguir lo justo de lo injusto.]

Tal y como recogió en 1470 el eminente jurista inglés John Fortescue, junto a las universidades tradicionales, en Londres se desarrollaron otras instituciones educativas (studium pupplicum) dedicadas a la formación profesional de los grupos sociales dominantes del reino. Además de proporcionar una formación en leyes avanzada, según su crónica, los Inns of Court (término que al no tener un equivalente en español podría traducirse, en este contexto, por colegio para la formación profesional de abogados) estaban orientados formar los modales de las elites del reino (Janin, op. cit., p. 113):

-Inns of Court form the manners of the knights, barons, and the greatest nobility of the kingdom

[-Los Inns of court forman los modales de caballeros, barones y de la alta nobleza del reino]

Uno de los casos más sonados de servilismo universitario a la monarquía fue la persecución de la Universidad de París a Juana de Arco para "complacer a su amo extranjero" (Le Goff, op. cit., p. 137), es decir a la corona inglesa. Cuando Inglaterra ocupó Paris durante la Guerra de los Cien Años, algunos miembros destacados de la universidad fueron reemplazados por clérigos favorables a Inglaterra. Como es sabido, la campesina Juana de Arco lideró al ejército francés a la victoria en Orleans derrotando a los ingleses, despertando así tanto una gran admiración como una fuerte animadversión. Cuando La Doncella fue capturada por los borgoñones, aliados de Inglaterra, la Universidad de París presionó para que fuese puesta bajo custodia inglesa y, poco después, para que fuese juzgada y castigada por hereje (cf. Janin, op. cit., p. 104). En dos cartas de Hérbert, rector de la Universidad de París, consta la persecución que encabezó. En la primera carta, dirigida al obispo Pierre Cauchon, abogaba por castigar a la hereje (Janin, op. cit., pp. 185-186):

-We (Hérbert and the University of Paris) ask Bishop Pierre Cauchon for the correction and punishment of the heretical woman called the Maid.

-We ask that this woman is quickly delivered to your power and that of the inquisitor of heresy.

-We ask that she is brought to Paris so that her case can be diligently examined and expertly judged to the edification of the Christian people and to the honor of God. 
[-Nosotros (Hérbert y la Universidad de París) pedimos al obispo Pierre Cauchon la corrección y castigo de la mujer hereje llamada la Doncella.

-Pedimos que esta mujer sea rápidamente entregada a su poder y al del inquisidor de la herejía.

-Pedimos que sea llevada a París para que su caso pueda ser diligentemente examinado y juzgado por expertos para la edificación del pueblo cristiano y el honor de Dios.]

En la otra carta, dirigida al monarca inglés Enrique VI, Hérbert reincide en su voluntad de que Juana debía sea juzgada por un tribunal eclesiástico (Janin, op. cit., p. 186).

-We (Hérbert and the University Paris) rejoice greatly with the delivery of the Maid to your power.

-We are confident that by your good offices the woman will be brought to justice to make amends for the great evils and scandals she has notoriously brought upon this kingdom.

-We urgently pray you to order that this woman be handed over to the justice of the Church in short order.

[-Nosotros (Herbert y la Universidad de París) nos regocijamos mucho con la entrega de la Doncella a su poder.

-Estamos seguros de que por su buen oficio la mujer será llevada ante la justicia para reparar los grandes males y escándalos que notoriamente ha traído a este reino.

-Os rogamos con urgencia para que ordenes que esta mujer sea entregada a la justicia de la Iglesia en el corto plazo.]

Tras esta solicitud, Juana fue juzgada por un tribunal religioso compuesto principalmente de graduados por la propia Universidad de París que eran partidarios de Inglaterra. La universidad anunció con satisfacción al Rey de Inglaterra su condena a muerte como culpable de herejía. Inmediatamente fue quemada públicamente.

Como han desarrollado Janin (op cit., pp. 94-96) y Le Goff (op. cit., p. 137), tras la reconquista de París la monarquía francesa mostró su desconfianza hacia la universidad y entabló un proceso para ponerla bajo su control. La universidad apoyó la política gálica y la Pragmática Sanción dictada por el rey Carlos VII, pero el monarca la privó igualmente de sus privilegios fiscales y judiciales y la sometió al parlamento. En 1446 emitió un comunicado oficial en el que decía que, en su reino, el rey no estaba sujeto a ningún hombre y que la creación de las corporaciones caía únicamente bajo su potestad y no de la del papa ni ninguna otra persona. A continuación dejaba establecido a quién debía servir la universidad (Janin, op. cit., p. 95):

-The university is the daughter of the king, bound to him in reverence, honor and subjection.

[-La universidad es la hija del rey, obligada a la reverencia, honor y sometimiento hacia el rey.] 
Poco después, en 1452, el legado papal Guillermo de Estouteville, actuando de parte del rey, llevó a cabo una reforma que preparaba el camino para un mayor control monárquico. En 1470, el rey Luis XI impuso a los maestros y estudiantes borgoñones el juramento de obediencia al monarca. Finalmente, en 1499 la universidad perdió un derecho conquistado fundamental como era el derecho a suspender las clases (derecho a huelga en términos modernos) y quedó en manos del rey.

\subsection{Servir al papado y a la jerarquía eclesiástica}

Durante la Edad Media fue el papado quien ofreció más privilegios a las corporaciones universitarias y, con ello, trató de asegurarse su apoyo. La Santa Sede apoyó a muchas universidades para que se desprendiesen de la jurisdicción y el control de los poderes locales (reales, comunales, eclesiásticos) y consiguió ponerlas bajo su jurisdicción. Esto suponía que los universitarios pasaban a estar sometidos a su autoridad. Esta sujeción se plasmó en el hecho de que, como indica Le Goff (1996, p. 76), "[l]os intelectuales de Occidente se convierten en cierta medida, pero con toda seguridad, en agentes pontificios".

Especialmente a través de la Universidad de París, la jerarquía católica trató de reforzar su hegemonía frente al auge de los poderes laicos. En las dos bulas que sentaron las bases de la Universidad de París, el papado establecía la prohibición de la enseñanza de derecho civil en beneficio de la teología y del derecho canónico.

La bula Super Speculam de Honorio III en 1219 es famosa por prohibir la enseñanza de derecho romano en París con el objetivo de fortalecer la teología (cf. Levillain, 2002, p. 734). Dice así (Denifle y Chatelain, 1889, pp. 90-93):

-Algunos de los prelados y cabildos de las iglesias con buena capacidad de aprendizaje deben dedicarse al estudio de la profesión teológica.

- Los reglares no deben retirarse a recibir lecciones de leyes o medicina.

-Los parisinos (La Universidad de París) no pueden enseñar ni aprender justicia civil (bajo pena de excomunión).

-(La Universidad de) París es el lugar donde se enseña teología.

El apartado de la bula del que se han extraído estos datos dice lo siguiente (ibíd.):

Honorius III innovat statutum Concilii Lateranensis IV de theologis per singulas metropoles statuendis; praecipit ut ab ecclesiarum praelatis et capitulis ad theologicae professionis studium aliqui docibiles destinentur, concedit studentibus in eadem facultate per quinque annos fructus beneficiorum suorum. Innovat decretum Concilii Turonensis, ne regulares exeant ad audiendum leges vel physicam, et extendit illud ad omnes clericos personatus habentes et ad presbyteros. Insuper statuit ne Parisiis sive in civitate sive aliis locis vicinis quisquam docere vel audire ius civile praesumat sub paena excommunicationis, et Parisios declarat locum, ubi theologia debeat doceri. 
[Honorio III renueva el estatuto del Concilio Lateranense IV, que trata sobre el establecimiento de teólogos en las metrópolis. Prescribe que algunos de los prelados y cabildos de las iglesias con buena capacidad de aprendizaje se dediquen al estudio de la profesión teológica y concede a los estudiantes disfrutar durante cinco años de los beneficios de la facultad. Renueva el decreto del Concilio Turonense, en el que se prohíbe que los reglares se retiren a recibir lecciones de leyes o medicina, y lo extiende a todos los que son considerados clérigos y a los presbíteros. Además ordena a los parisinos de la ciudad de París o de la vecindad que ninguno pretenda enseñar o aprender justicia civil, bajo pena de excomunión, y declara un lugar a los parisinos donde se enseñe teología.]

En 1231 Gregorio IX emitía la bula Parens Scientarum en la que se fijaban los estatutos de la Universidad de Paris. Hoy en día se considera su carta magna. En ella, el papa incidía en la enseñanza de teología y derecho canónico (Halsall, 1996b; Munro, 1897, pp. 7-11; Thorndyke, op. cit., pp. 35-9).

-Suitable masters of the University of Paris teach theology.

-Suitable masters of the University of Paris teach canon law.

-Masters and students should become God's learned.

[-Maestros adecuados de la Universidad de Paris enseñan teología.

- Maestros adecuados de la Universidad de Paris enseñan derecho canónigo.

-Los maestros y los estudiantes deben ser doctos en Dios.]

No fue esta la única manera en las que las universidades debían colaborar con la jerarquía. En primer lugar, en las universidades se trató de apartar a los movimientos estudiantiles contrarios al orden establecido, concretamente a los goliardos (misión 1.2.1.). Además, las universidades sirvieron como instrumento para propagar la fe y hacer proselitismo religioso (misión 1.2.2.), así como para identificar y condenar las herejías (misión 1.2.3.). Ya fuese por la vía de lo que se difundía como de lo que se reprendía, la iglesia trató de circunscribir el universo del pensamiento a aquello que se ajustase a su visión del mundo. Sin embargo, a pesar del control ejercido por las autoridades, las corrientes disidentes se suceden en las universidades. La misión institucional de las universidades controladas por el papa estaban orientadas a favorecer los intereses y perspectivas de la jerarquía católica, pero hubo otras voces que impulsaron con fuerza un pensamiento contestatario.

\subsubsection{Apartar a los movimientos contrarios al orden establecido (los goliardos)}

Los goliardos constituyeron un movimiento intelectual contestatario que intentó vivir en libertad, criticó a los altos estamentos y promovió la transgresión de la moral y de las costumbres establecidas. El movimiento apareció en el siglo XII y desapareció a lo largo del XIII, tiempo durante el cual fue tratado con hostilidad por razones obvias. Se trata de un movimiento estudiantil genuinamente anti-sistema que opera en el marco de una institución controlada por los altos estamentos y orientada hacia la reproducción social. Tanto por la 
novedad como por la radicalidad de su visión del mundo merece un análisis sobre sus componentes y sus ideas. A continuación se presenta un resumen a partir de la descripción que proporcionan Janin (op. cit., pp. 35-39), Martínez (1996) y especialmente Le Goff (op. cit., pp. 39-47):

Los goliardos eran estudiantes pobres y vagabundos sin domicilio fijo que iban de universidad en universidad siguiendo a los maestros y las enseñanzas que más les atraían. Aunque algunos de ellos acabaron trabajando para los estamentos altos, generalmente los goliardos escaparon de las estructuras establecidas y ejercieron como juglares y bufones para obtener ingresos y comida. Sus cantos y poemas -recogidos en Carmina burana- trataban fundamentalmente del amor, el sexo, la fortuna, el juego y el vino. Bajo estos temas aparentemente livianos, se desarrolla una visión del mundo rupturista que suscitó la indignación de los tradicionalistas y desembocó en su persecución y condena. La exaltación de un modo de vida centrado en los placeres terrenales transgredía el orden moral y las costumbres que defendía la jerarquía católica. Sus canciones glorificaban los placeres de la vida activa en el paraíso terrenal frente a la vida contemplativa que busca la salvación fuera del mundo, lo cual, según Le Goff, hace de los goliardos unos precursores del humanismo renacentista. Para este autor, otro aspecto en el que plantean una ruptura con el pensamiento tradicional es el tratamiento que hacen del tema de la fortuna, puesto que niegan el progreso y que la historia tenga un sentido, lo cual se opondría a la determinación perfecta del Plan Divino. Además, en la poesía goliardesca son recurrentes las críticas explícitas a la iglesia, a sus leyes, a su doctrina, a su conducta y a su amasamiento de riqueza, lo cual es sintomático de su actividad de promoción de una cultura laica en el marco urbano.

Como muestra del rechazo de los goliardos hacia la iglesia y hacia el mismo Dios, se pueden resaltar tres ideas que contiene su canción Credo. En ella, un sacerdote anima a un goliardo a hacer su última confesión en el lecho de muerte y éste responde parodiando el Credo y afirmando, entre otras cosas, lo siguiente (Janin, op. cit., p. 38):

-The goliard never thinks of God.

-The goliard cares little for sin.

-The goliard does not want his resurrection.

[-El goliardo nunca piensa en Dios.

-El goliardo se preocupa poco por el pecado.

-El goliardo no quiere su resurrección.]

La iglesia no fue el único objetivo de los goliardos. Su crítica social se centraba en todos los estamentos medievales, particularmente en los altos cargos del poder. Según Le Goff (op. cit.) los goliardos se oponen a todo un orden social jerarquizado. Al noble le niegan su privilegio de nacimiento, oponiendo un nuevo orden fundado en el mérito. A las armas y a las hazañas guerreras de los caballeros y militares, anteponen los combates del espíritu y las justas de la dialéctica. Incluso llegan a mostrar desprecio por el mundo rural, como hombres de ciudad que aborrecen a los campesinos rústicos. 
Como era previsible, los goliardos fueron objeto habitual de persecución y condena por parte de los representantes del orden, especialmente por la jerarquía eclesiástica. Como sugirió un monje del siglo XII, no era aceptable la desviación moral de los goliardos (Haskins, 2002, p. 112):

-The wandering clerks do not learn morals.

[-Los estudiantes vagabundos no aprenden la moral.]

A nivel institucional, la jerarquía católica deliberó sobre los goliardos en varios concilios y sínodos eclesiásticos. Martínez (op. cit., p. 459) proporciona diversos ejemplos. El primero de ellos es el Concilio de Tréveris de 1227 en el que se ordenó a los curas párrocos que vigilasen a los vagos scholares aut goliardos (estudiantes vagabundos o goliardos) para que no interrumpiesen la misa con sus cánticos. Además, indica que en los Concilios de Cháteau Gonthier y de Rouen se determinó que a los clerici ribaudi, máxime qui dicuntur de familia Goliae, qui "goliardi" nuncupantur (a los clérigos rebeldes, sobre todo a los que son de la familia de Golías, los llamados goliardos) no se les hiciera la tonsura, signo distintivo de los clérigos. Añade que en 1239 se generalizó la orden de cortarles el pelo al rape. Según el mismo autor, los goliardos recibieron la puntilla con la condenación del Concilio de Cahors en 1289. En la prohibición se establecía lo siguiente (Wright, 1841, p. xii):

-Item, praecipimus quod clerici non sint joculatores, goliardi, seu bufones. [-Ningún clérigo debe ser juglar, goliardo o bufón.]

Los estatutos diocesanos de 1350 repetían esta prohibición (Symes, 2007, p. 157):

-Clerics must not show themselves off as goliards or buffoons.

[-Los clérigos no deben lucirse como goliardos o bufones.]

El movimiento universitario goliardo tuvo una breve existencia, desintegrándose a lo largo del siglo XIII. Es sintomático de la aversión que sentía la jerarquía católica por los goliardos el hecho de que incluso después de haber desaparecido, siguiesen siendo objeto de condenas. Que fuese condenado y prohibido por las autoridades eclesiásticas a las que estaban supeditadas las universidades indica que, a nivel institucional, no debían dar cabida a los goliardos. Según Verger (1992, p. 157), todas las universidades medievales estaban obsesionadas por la lucha contra el estudiante vagabundo $y$ descontrolado que iba de un maestro a otro. Las universidades introdujeron dos filtros institucionales en los requisitos de admisión con el objetivo de apartar a los estudiantes vagantes. Muchas universidades requirieron, desde el principio, que los estudiantes estuviesen necesariamente adscritos a un maestro y, especialmente a partir del siglo XIV, que residiesen en los colegios mayores y residencias autorizadas. Por ejemplo, la Universidad de Oxford impuso, con el apoyo de la monarquía, la obligación de residir en colegios mayores en el año 1420, mientras que la Universidad de Viena aprobó ordenanzas contra los estudiantes de fuera (extra bursas stantes) en 1410 y la de Paris contra los llamados Martinets (otro tipo de estudiantes libres que en muchos casos no tenían maestro) en 1452-7 (Janin, op. cit., p. 35; Schwinges, 1992a, p. 219). 
Por otro lado, desde los orígenes de la universidad, los estudiantes se vieron obligados a tener un maestro permanente. Como recogen Janin (op. cit., p. 35) y Schwinges (1992b, p. 173), este requisito consta ya en los estatutos de la Universidad de París de 1215 (Original en latín en Denifle y Chatelain, op. cit., pp. 78-80; Traducción al inglés en Halsall, 1996c; Munro, op. cit., pp. 12-15; Thorndyke, op. cit., pp 27-30; Traducción al castellano en Cerda, 2010, pp. 78):

-Nullus sit scholaris Parisiuis qui certum magistrum non habeat. -[No debe haber ningún estudiante que no tenga un maestro fijo.]

Según Schwinges (1992b, p. 173), se dieron casos similares en Montpellier (1220), Oxford (antes de 1231), Cambridge (después de 1236) y en universidades de Europa central.

\subsubsection{Propagar la fe y hacer proselitismo religioso}

La difusión de la fe desde las universidades aparece recurrentemente en la documentación de la Baja Edad Media relacionada con la institución. Por ejemplo, en la bula para la fundación de la pequeña universidad de Dole en Borgoña, 1422, Martín V sentenciaba que (Compayré, op. cit., p. 18):

-By the study of letters the worship of divine things increases and the catholic faith is fortified.

[-Mediante el estudio de las letras aumenta el culto a las cosas divinas y se fortalece la fe católica.]

En 1431 Eugenio IV recogía en la fundación de la Universidad de Poitiers la misma idea (ibíd.):

-Thanks to the study of letter, the worship of God is increased; they prepare the salvation of souls.

[-Gracias al estudio de las letras, aumenta el culto hacia Dios; preparan para la salvación de las almas.]

La bula de Nicolás $\mathrm{V}$ concediendo a la universidad de Barcelona las gracias y privilegios de la de Tolosa en 1450 proporciona otro ejemplo (ibíd.):

-Thanks to the new studium generale, the Catholic faith would be extended in that region (ibidem fides Catholica dilatetur).

[-Gracias al nuevo studium generale, la fe católica se extendería en la región (ibidem fides Catholica dilatetur).]

Además, hubo autoridades e intelectuales que promovieron la enseñanza de idiomas con el propósito de convertir a los infieles. Por ejemplo, el papa Inocencio IV escribió en 1248 al canciller (rector) de la Universidad de París dando la siguiente orden (Denifle y Chatelain, op. cit. p. 212):

-Cancellario [Parisiensi]. Quia cordi nobis est illa debita meditatione perficere, per que salus animarum proveniat et fidei christiane religio dilatato tentorii sui 
loco funiculos suos faciat longiores, quosdam pueros tam in arabica quaiii in aliis linguis orienlalium partium peritos Parisius mitti disposuimus ad studendum, ut in sacra pagitia docente vias mandatorum Domini eruditi alios in ultramarinis partibus erudiant ad salutem. Ne igitur iidem pueri, qui jam sunt decem Parisius, ab incepto sludio pro necessariorum defectu desistere compellantur, mandamus, quatinus, etc.

[-Resumen: Diez estudiantes deben estudiar árabe y otras lenguas orientales en París para ser enviados al extranjero para la salvación de las almas a través de la religión cristiana.]

La orden dominica, que entró en la Universidad de París en 1217 con el apoyo del papa, fue una de las más activas en el proselitismo religioso. En el año 1256 el escolástico de París y quinto general de la orden Dominica, Humbert de Romans, describió de la siguiente manera la labor que los eruditos que hablan lenguas extranjeras desempeñaban como misionarios (Thorndyke, op. cit., pp. 68-70):

-Some brothers made the decision to leave their own nation and cross to barbarous nations and to sweat at learning letters and foreign languages to spread the name of our lord Jesus Christ and his glory.

-Those brothers labor in diverse provinces at the extirpation of wicked heresy (many Cumani have been baptized, the Maronites have offered their books for correction, friars in Spain have made for salvation of the Saracens, they have also been in the remotest parts of the Orient with the Georgians, many Prussians have left pagan rites and hastened to the grace of baptism).

[-Algunos hermanos tomaron la decisión de salir de su propia nación y cruzar a las naciones bárbaras y sudar en el aprendizaje de las letras y las lenguas extranjeras para difundir el nombre de nuestro Señor Jesucristo y de su gloria.

-Esos hermanos trabajan en diversas provincias en la extirpación de la herejía malvada (muchos cumanos han sido bautizados, los maronitas han ofrecido sus libros para ser corregidos, los frailes en España han trabajado en la salvación de los sarracenos, también han estado en los lugares más remotos de Oriente con los georgianos, muchos prusianos han abandonado los ritos paganos y se han apresurado en la gracia del bautismo).]

El mallorquín Ramon Llull fue uno de los principales impulsores de la enseñanza de lenguas orientales. Temeroso del daño que podían causar las doctrinas religiosas de los sarracenos, judíos y tártaros a la cristiandad, en 1298-1299 solicitó que se fundara y financiara un estudio de idiomas (ibíd., pp. 125-127):

-At Paris, where the fountain of divine wisdom raises, where the light of truth shines on Christian peoples, there should be founded study of Arabic, Tartar and Greek, [so] that we, having learned the languages of adversaries of God and ourselves, by preaching to and teaching them may overcame their errors in the sword of truth and render the people acceptable unto God and convert enemies into friends (and in this way) Christendom will receive the greatest exaltation and extension. 
[-En París, donde se eleva la fuente de la sabiduría divina, donde la luz de la verdad brilla en los pueblos cristianos, debería fundarse un estudio del arábigo, del tártaro y del griego, (de manera que), habiendo aprendido las lenguas de los enemigos de Dios y de nosotros mismos, a través de la predicación y de la enseñanza se puedan superar sus errores con la espada de la verdad y hacer que la gente acepte a Dios y convertir a los enemigos en amigos (y de ese modo) la cristiandad recibirá la máxima exaltación y extensión.]

La implicación de Llull en la campaña por la enseñanza de lenguas orientales para propósitos misioneros desembocó en el decreto del Consejo de Viena de 1312 (ibíd., pp. 149-150):

-Courses in Hebrew, Greek, Arabic and Aramaic languages should be established so that catholics acquainted with the languages that the infidels use may come to know the infidels themselves and be able to instruct them in sacred institutions and add them to the company of worshipers of Christ by knowledge of the Christian faith and reception of baptism.

-Courses in these languages are to be established wherever the Roman curia happens to reside and also in the universities of Paris, Oxford, Bologna, and Salamanca so that they may spread the faith salubriously to infidel nations.

[-Cursos en hebreo, griego, árabe y arameo deben ser implantados para que los católicos familiarizados con los idiomas que usan los infieles puedan llegar a conocer a los propios infieles y sean capaces de instruirles en las instituciones sagradas y de sumarlos a la compañía de los fieles de Cristo mediante el conocimiento de la fe cristiana y la recepción del bautismo.

-Cursos de idiomas han de establecerse allí donde la curia romana resida y también en las universidades de París, Oxford, Bolonia y Salamanca para que puedan difundir la fe saludablemente a las naciones infieles.]

Como ha señalado Thorndyke (ibíd., p. 125), Llull además persuadió al rey de Aragón en 1276 para que estableciese una facultad para el estudio de arábigo en la Universidad de Mallorca. Este autor (Ibíd.) también indica que un capítulo provincial de 1250 en Toledo seleccionó a ocho dominicos para que estudiasen arábigo y que, en Valencia, Joan de Periguentos fundó una facultad con el mismo propósito en 1281, mientras que Ramón Martini enseñó dicha lengua en Barcelona. También Pierre de Blois promovió la enseñanza de lenguas con fines misioneros en su plan educativo de 1309 (cf. ibíd., pp. 138-149).

\subsubsection{Identificar y condenar las herejías}

Es sabido que durante la Edad Media las ideas que planteaban desviaciones respecto a la doctrina oficial se tacharon de heréticas y fueron condenadas. Los documentos que se han analizado muestran que, desde el mismo seno de las universidades, surgieron herejías y que a nivel institucional, tanto desde la propia universidad como de las autoridades eclesiásticas externas, fueron perseguidas y prohibidas. Al estar sometidas al auspicio pontifical, las universidades europeas fueron empujadas a colaborar en la lucha universal del 
papado contra las herejías. La condena de las corrientes heréticas tiene varias dimensiones. En el presente trabajo se exponen solamente fuentes referidas al desarrollo y condena de las doctrinas heréticas del maestro John Wycilif en la Universidad de Oxford. Este proceso destaca por la contradicción que se produjo entre la misión institucional asignada por el papado de promover la ortodoxia cristiana y perseguir las herejías y la posición pro-Wyclif que adoptan la mayor parte de los miembros y autoridades destacadas de la Universidad de Oxford.

Durante el siglo XIV, el maestro John Wyclif desarrolló una doctrina herética que sus seguidores, el movimiento lolardo o wyclifista, expandieron por Inglaterra, especialmente en la Universidad de Oxford, y que entró en conflicto con los garantes de la ortodoxia. Según desarrolla la Stanford Encyclopedia of Philosophy (Conti, 2011), Wyclif fue un precursor de la Reforma Protestante que lideró un movimiento de oposición a la iglesia católica y a algunos de sus dogmas e instituciones. El filósofo y teólogo reclamó la supremacía del rey sobre el clero y sostuvo una interpretación distinta de la verdad Bíblica fundada en su propio modelo metafísico. Tradujo la Biblia al inglés para hacerla accesible al pueblo llano, atacó los abusos y la riqueza de la iglesia y se opuso a la doctrina de la transustanciación. Sus tesis heterodoxas ponían en riesgo la hegemonía de la verdad de la iglesia católica, por lo que pronto fueron condenadas. Entre las condenas, se pueden destacar las veinticuatro proposiciones prohibidas por el Arzobispo Courtenay en 1382, la condena del papa Gregorio XI el mismo año, la prohibición del sínodo provincial de 1407 en Oxford o la condena de sus escritos y el mandato de quemar sus libros en el Concilio de Constanza (1414-1418). Con el fin de ilustrar el intento de imponer a la Universidad de Oxford la misión de prohibir las doctrinas de Wyclif, se recoge la información que proporcionan la condena del papa y la prohibición del sínodo.

El papa Gregorio XI no anduvo con contemplaciones. Mandó encarcelar a Wyclif y apercibió a la Universidad de Oxford para que siguiese la ortodoxia y prohibiese la doctrina hereje (Halsall, 1998; Thatcher, 1907, pp. 378-382):

-The Chancellor and the University of Oxford ought to be warriors and champions of the orthodox faith.

-The University of Oxford (has acted with) contempt for the Roman Church.

-The university of Oxford (has caused) injury to the orthodox faith.

-John de Wycliffe, rector of the church of Lutterworth, in the diocese of Lincoln, Professor of the Sacred Scriptures (would that he were not also Master of Errors) dogmatizes and publicly preaches heretical dogmas.

-Wycliffe's heretical dogmas strive to subvert the state of the whole church.

-Wycliffe's heretical dogmas strive to subvert secular polity.

-The University of Oxford must not permit to be asserted or proposed to any extent whatever, the opinions, conclusions, and propositions which are in variance with good morals and faith.

[-El canciller y la Universidad de Oxford deben ser guerreros y campeones de la fe ortodoxa.

-La Universidad de Oxford (ha actuado con) desprecio por la Iglesia Romana. 
-La Universidad de Oxford (ha causado) daño a la fe ortodoxa.

-John de Wycliffe, rector de la iglesia de Lutterworth, en la diócesis de Lincoln, profesor de las Sagradas Escrituras (que no sea también maestro de los errores) dogmatiza y predica públicamente dogmas heréticos.

-Los dogmas heréticos de Wycliffe se afanan en subvertir el estado de toda la iglesia.

-Los dogmas heréticos de Wycliffe se afanan en subvertir la política secular.

- La Universidad de Oxford no debe permitir que se afirme o se proponga en medida alguna las opiniones, conclusiones y proposiciones que no concuerdan con las buenas costumbres y la fe].

Según Deanesly (1920, pp. 231-232), cuando se emitió esta condena, el rector de la Universidad de Oxford y otras autoridades ya estaban del lado de Wyclif. Excepto los frailes predicadores, toda la universidad le apoyaba. En consecuencia, la universidad, que a estas alturas había conseguido poder y estaba imbuida por las doctrinas anti-papales, consideró que las tesis condenadas eran ortodoxas pero que podían llevar a interpretaciones equivocadas, por lo que Wyclif debería explicarlas en Londres (Jusserand, 2007, p. 424). Esta benevolencia con el hereje levantó la indignación de algunos eruditos ortodoxos. El cronista principal de la época, Thomas Walsingham, criticó la supuesta degeneración de la Universidad de Oxford (Riley, 1860, pp. 344-346):

-Oxoniense studium generale quam gravi lapsu a sapientiæ et scientiæ culmine decidisti!... Pudet recordationis tantæ impudentiæ.

[-¡Estudio General de Oxford, con qué profundidad caíste del culmen de la sabiduría y de la ciencia! Me abochorno con el recuerdo de tanta impudencia / desvergüenza.

Las condenas orientadas a que la universidad no permitiese la difusión de la doctrina hereje continuaron. La sexta constitución del sínodo provincial de Oxford de 1407 dejaba clara la misión institucional como censores que debían adoptar las universidades de Oxford y Cambridge en pro de la eliminación de las herejías (Robson, 1961, p. 244):

-Because new ways are frequently more seductive than old, we will and command that no tract or treatise of master John Wyclif or anyone else, composed in his day or since or to be composed in the future, shall be henceforth read [...], unless it shall have been examined by the University of Oxford or Cambridge [...]; and having been examined, shall have been expressly approved unanimously by the same, and then by us and our successors. Should anyone have read such tracts or treatises in the schools or have taught contrary to this procedure, let him be punished as a sower of schism and promoter of heresy.

-[Debido a que las nuevas maneras son frecuentemente más seductivas que las viejas, ordenaremos y ordenamos que ningún folleto o tratado del maestro John Wyclif o de cualquier otro redactado en su día, desde entonces o que será escrito en el futuro, sea leído de ahora en adelante (...), a menos que haya sido 
examinado por la Universidad de Oxford o de Cambridge (...); y que habiendo sido examinados, deberán haber sido expresamente aprobados de modo unánime por los mismos y después por nosotros y nuestros sucesores. Si alguien ha leído tales folletos o tratados en las escuelas o han enseñado en contra de este procedimiento, sea castigado como un sembrador de cismas y promotor de herejía.]

No fueron estas las únicas condenas y críticas que recibió el wyclifismo. Para profundizar, son útiles los trabajos de Deanesly (op. cit., pp.225-251) y Robson (op. cit.), quienes proporcionan información detallada que recoge un número considerable de fuentes primarias en torno a las ideas del wyclifismo, su represión y la respuesta de sus miembros. A partir de la bibliografía que se ha consultado, se puede concluir que las autoridades externas tuvieron éxito en silenciar el movimiento en Oxford, pero eso no evitó que se sentasen algunas de las bases que permitieron la Reforma.

\subsection{Contribuir al desarrollo de las ciudades}

Este epígrafe está dedicado a los vínculos entre las universidades medievales y el desarrollo de las ciudades y de la vida urbana. La ciudad o burgo constituye el hábitat de la universidad y permite su reproducción. En la Baja Edad Media, el papado ya no goza de absoluta hegemonía, sino que tiene que hacer frente al auge de los poderes terrenales locales. Como es sabido, desde los siglos XII-XIII se empiezan a desarrollar las ciudades (y ciudades-estado) más importantes y se produce un florecimiento del comercio. Allí el poder lo ejercen las autoridades políticas locales y la burguesía, es decir los habitantes de los burgos que no pertenecían a ninguno de los estamentos tradicionales, sino que se dedicaban fundamentalmente al comercio. Especialmente a partir del siglo XV, como señala Braudel (1986), Europa experimenta un resurgir general de la economía que beneficia a las ciudades y a las élites económicas urbanas que ejercen el poder. Según el autor, en las ciudades empieza a desarrollarse tanto la economía de mercado, que define como aquella que está sometida a la competencia -a las leyes de la oferta y la demanda-, como del capitalismo, entendido como la economía que controlan y monopolizan los grandes capitalistas en su favor y al margen de la competencia, si bien estas economías serán minoritarias hasta los siglos XVIII y XIX ${ }^{3}$. Polanyi (1989) coincide en señalar que desde finales de la Edad Media se produce un desarrollo de las relaciones de mercado que alcanzará plenitud en el siglo XIX. En lo que concierne a la universidad, Contoni y Yuchtman (op. cit.) han encontrado que la universidad cumplió un rol importante en la expansión de la actividad económica o "revolución comercial" en las ciudades durante los últimos siglos del periodo medieval. Además, según los autores, la relación entre las universidades y una mayor actividad comercial impulsó el desarrollo de instituciones legales y administrativas.

En términos generales, se puede hablar de un periodo en el que se producen vínculos incipientes entre el desarrollo de las universidades y el de las ciudades

\footnotetext{
${ }^{3}$ La diferencia entre economía de mercado y capitalismo es un aspecto central de la obra de Braudel. En el libro que se cita el lector podrá profundizar en las características diferenciales de cada modelo.
} 
y la vida urbana. Tanto la ciudad como la universidad se verían favorecidas por esta relación. Sin embargo, las relaciones simbióticas entre ambos actores no se produjeron de inmediato. Rüegg (op. cit., pp. 18-19) argumenta que, en un primer momento, las circunstancias sociales no favorecían que se desarrollase dicho vínculo. Más bien, la situación era de conflicto. Las ciudades no necesitaban a las universidades para satisfacer sus necesidades profesionales, económicas, políticas o legales y veían con recelo al aumento del poder de los universitarios en la vida urbana. Las universidades, por su parte, defendían mediante privilegios a los estudiantes y maestros de los abusos a los que les sometían las autoridades municipales en relación a los impuestos, tasas, peajes, hospedajes, agresiones, etc. Sin embargo, prosigue el autor (ibíd.), a partir de finales del siglo XIII las grandes ciudades comerciales empiezan a reconocer las ventajas que suponía contar con una universidad. A partir de este momento, comienza un proceso de integración de las universidades en el devenir de las ciudades que se desarrollará con mayor fuerza durante el Renacimiento. Como describe Rüegg, (ibíd.), la formación universitaria se percibe como fundamental para la preparación de funcionarios y consejeros capaces de velar por los intereses y el poder de las ciudades y del gobierno municipal. Surgió una demanda de legistas formados en las universidades que pudiesen solucionar nuevos problemas legales desconocidos para el derecho común, parte de los cuales se derivaban de las nuevas actividades comerciales. Además, contar con universidades en territorio propio permitía evitar la emigración de los estudiantes locales a otras tierras, atraer a estudiantes forasteros adinerados que activarían el consumo interno y contar con un centro de prestigio que permitiría competir en mejor disposición con otras ciudades.

Como sugieren Pirenne (1983, pp. 150-152), Ponce (2005, pp. 95-98) y Rüegg (op. cit.), los consejos municipales fundaron nuevas instituciones de enseñanza para que estudiasen los hijos de los burgueses y se emplearon por asumir su control para conseguir acabar con el duopolio del clero (papado) y de la nobleza (imperio y monarquías) y participar en los beneficios que procuraba la educación superior. La burguesía buscaba beneficiarse del aprendizaje de conocimientos que fuesen útiles para el desempeño de sus responsabilidades económicas y políticas. Además, los títulos de educación universitaria proporcionaban una carta de franquicia que la burguesía empleó para apoderarse de los cargos más importantes en el gobierno, la justicia, las embajadas y la burocracia. En las ciudades-estado los gobiernos municipales asumieron crecientemente el gasto de los salarios de los maestros y las universidades cayeron bajo control de la oficialidad local. Por ejemplo, en Salamanca las autoridades locales presionaron para colocar a representantes de intereses comunales como miembros de las autoridades universitarias (Beltrán de Heredia, 1970). La emergente burguesía mantenía una devoción religiosa ferviente, pero entró en conflicto con las autoridades eclesiásticas por el control de la universidad e impulsó un modelo educativo de carácter laico que respondiese mejor a sus expectativas vitales y laborales.

Para el presente trabajo, se han consultado fuentes que muestran que algunas autoridades otorgaron a la universidad la potestad de elegir a parte de los gobernantes de la ciudad. Además, se han analizado otras fuentes que 
contienen referencias al prestigio, distinción y bienestar que según las autoridades proporcionaría la universidad a la ciudad.

Un ejemplo del vínculo entre la universidad y la ciudad se encuentra en una ordenanza del rey Jaime II de Aragón de 1321 en la que queda patente que la ciudad de Gerona se apoyaba en la universidad para asuntos de gobierno (Bofarull y Mascaró, 1851, pp. 172-173.)

-La universidad de Gerona (junto a los prohombres de esta villa) puede nombrar todos los años tres o cuatro jurados ó cónsules para el gobierno de Gerona.

En otra ciudad del reino de Aragón, Mallorca, la situación era similar. En 1377, Pedro IV el Ceremonioso reafirmaba una concesión otorgada por Jaime I el año 1249 en los siguientes términos (ibíd., pp.199-205)

-Probis hominibus et universitati Majoricarum presentibus et futuris imperpetuum quod liceat vobis habere imperpetuum sex juratos habitatores tamen civitatis Majoiicarum et regni et liceat eisdem jtiratis gobernare et administrare et regere totam insulam ad fidelitaletn et comuue comodum universitatis.

[-Los hombres buenos y la Universidad de Mallorca tienen la posibilidad de elegir seis jueces residentes en la ciudad o en el reino para que gobiernen, administren y rijan la isla para el bien común de la universidad.]

Por otra parte, algunas autoridades justificaron la instauración de universidades bajo el argumento de que traería bienestar a la ciudad y a los ciudadanos. Como señalan Claramunt (1994, p. 46) y Fernández Luzón (2003, p. 37), aunque las magistraturas urbanas y el Consejo de Ciento se habían opuesto en un principio a la creación de una universidad en Barcelona porque consideraban que podría en riesgo el bienestar de la ciudad, a mediados del siglo XV los consellers reconsideraron su política y entendieron que su creación podía contribuir a superar el marasmo demográfico y económico de la ciudad. En una reunión de 1448 deliberaron sobre la creación de la universidad con el argumento de que (ibíd.):

-En aquesta ciutat són totes coses pertanyents a ciutat insigna e notable sino que ych fall Studi general, qui l'ennobliria molt, e los fills dels ciutadans haurien ocassió d'acquirir sciència e a la dita ciutat ne reportaría gran profit e fama.

-[En esta ciudad todas las cosas pertenecen a la ciudad insigne y notable, si no fuese porque falta un Estudio general que lo ennoblecería mucho, y los hijos de los ciudadanos tendrían la ocasión de adquirir ciencia en dicha ciudad, lo cual reportaría gran provecho y fama.]

Dos años más tarde el Consejo de la ciudad aprobó la propuesta y el jurista Guillem Jordà emitió un informe en el que recomendaba solicitar al rey y al papa sendas provisiones para fundar un estudio general. Es de destacar el hecho de que, en su opinión, el rector debía carecer de jurisdicción y los estudiantes de fuero particular, de modo que la universidad dependiera del Consejo de Ciento y del capítulo catedralicio (ibíd.). 
El mismo año, el monarca Alfonso el Magnánimo concede un privilegio a los consellers, basado en el memorial que le presentaron los embajadores de la ciudad, que les autorizaba a estatuir una universidad en Barcelona. El argumento del monarca se hacía eco de las aspiraciones de las autoridades locales (Claramunt, op. cit., p. 46):

-The University is reasonable and useful for the common weal of the city. [-La universidad es razonable y útil para el bienestar común de la ciudad.]

También el papa Nicolás $\mathrm{V}$ expidió una bula fundacional del estudio general el mismo año. Como señala Fernández Luzón (op. cit., p. 38), la diferencia entre ambas cartas fundacionales es que, mediante la bula, era el propio papa el que fundaba el estudio, mientras que el monarca solamente autorizaba a la ciudad a erigir la universidad. El autor añade (ibíd., pp. 38-39):

Sobre esta potestad, que marcaría la historia del Estudio Barcelonés hasta convertirlo en uno de los paradigmas de la universidad municipal, el ayuntamiento construiría el régimen jurídico de la institución, asumiendo el papel de suprema autoridad universitaria y arrogándose atribuciones normalmente reservadas a reyes y pontífices.

En este sentido, el privilegio de Alfonso el Magnánimo señaló el punto de inflexión hacia el abierto intervencionismo de las autoridades ciudadanas, que dedicaron un considerable esfuerzo argumentativo a demostrar su derecho de patronazgo y la naturaleza municipal del Estudio desde el momento mismo de su fundación, aunque todavía en el siglo XVII el tema seguía siendo objeto de debate. La amplia discrecionalidad que Alfonso $\mathrm{V}$ concedió a los consellers para fundar y organizar el Estudio General explica por qué la ciudad siempre invocó este privilegio para fundamentar su derecho a controlar la institución docente, al margen del gremio universitario y de cualquier injerencia exterior.

El auge de las ciudades y su cercana relación con las universidades fue particularmente notable en Italia. Por ejemplo, la élite política que regía Perugia trató de promover la ciudad proponiendo en los Estatutos Municipales de 1285 que se crease una universidad (Università degli Studi di Perugia, s.f.):

-Studium ut civitas Perusii sapientia valeat elucere et in ea Studium habeatur. [-Que haya un Studium en Perugia para que la ciudad brille con conocimiento.]

El prestigio que adquirió el estudio sirvió para que, mediante un Estatuto de 1306, se reconociesen los privilegios de los asistentes y se pudiesen organizar en una universitas o corporación (Scolaribus qui sunt et pro tempore erunt in civitate Perusii sit licitum universitatem constituere) (ibíd.). Una vez reconocidos como corporación, la universidad obtuvo la potestad de participar activamente en el gobierno de la ciudad (ibíd.). Dos años más tarde, el papa Clemente $\mathrm{V}$ concedió validez y reconocimiento universal a los cursos que se impartían mediante la bula Super specula. 
En la bula de Juan XXII mediante la que se confirmaban las cátedras en derecho civil y canónico y se creaban plazas en medicina y artes (1321), se incidía en que la universidad de Perugia beneficiaría a la ciudad (Walsh, 1908, pp. 150-153):

-The University of Perugia will distinguish the city.

[-La Universidad de Perugia distinguirá a la ciudad.]

Finalmente, un decreto del emperador Carlos IV de 1355 otorgaba a la corporación el rango de universidad imperial. Se concedía a la ciudad el derecho permanente de albergar una universidad y procuraba ventajas económicas y seguridad para entrar y salir a todos aquellos que quisiesen acceder al estudio, incluyendo a los que venían de tierras lejanas (Università degli Studi di Perugia, op. cit.). El nuevo estatus y las ventajas fueron concedidas para ayudar a la ciudad a lidiar con las consecuencias nefastas de la plaga de 1348-49 (Brown, 1911).

Por último, conviene señalar que no era nada extraño que las autoridades locales prohibiesen a los maestros y estudiantes acudir a otras universidades. Uno de los muchos ejemplos se encuentra en la Designación de la ciudad de Lérida para erigir el Estudio General de todo el reino de Aragón (1300), en la que el rey Jaime II establecía lo siguiente (Villanueva, 1851, pp. 196-198):

-...Nulla persona... tam audax reperiatur, quod in aliquo loco terrae et dominationis nostrae... iura canonica vel civilia, aut libros medicinae sive philosophiae audeat vel praesumat aliquibus scolaribus legere vel docere...

[-Que no se encuentre persona... que sea tan audaz que en algún otro lugar de la tierra y de nuestro dominio... ose o pretenda aprender o enseñar derecho canónico o civil a otros...]

En resumen, la irrupción de la ciudad, en el marco del inicio del tránsito del feudalismo a un modelo de desarrollo basado en el mercado y en el capitalismo, sitúa a la universidad bajo la influencia de sus mandatarios políticos y sus élites económicas. Como escribe Pirenne (op. cit., p. 152), "[l]aica y mística a la vez, la burguesía medieval se encuentra de esta manera singularmente bien preparada para el papel que habrá de desempeñar en los dos grandes movimientos de ideas del porvenir: el Renacimiento, hijo del espíritu laico, y la Reforma, hacia la que conducía el misticismo religioso". La relevancia social de la clase emergente aumentará progresivamente y ejercerá un papel importante en la orientación de las universidades hacia la promoción del humanismo renacentista y de la Reforma.

\section{Conclusiones}

El modelo de misión universitaria en la Baja Edad Media consistió en proporcionar una mediación social orientada a beneficiar a los principales poderes sociales. Los altos estamentos y las élites municipales -a menudo en conflicto y otras veces llegando a consensos- entendieron que las universidades eran unan valioso recurso que había que controlar y orientar 
hacia la reproducción de su respectivo poder. Los documentos que se han analizado muestran que el papado y la jerarquía católica empujaron a las universidades más importantes como Bolonia, París, Oxford o Salamanca a colaborar en la propagación de la fe, así como a otras más pequeñas como Dole, Poitiers o Barcelona. La mayor parte de universidades medievales también tuvieron que participar en la lucha contra las herejías y otros movimientos contestatarios. Además, en París, los pontífices prohibieron derecho romano e impulsaron derecho canónico y teología. Por su parte, los emperadores reconocieron la Universidad de Bolonia y fundaron la de Nápoles con el objetivo de fortalecer el poder del sacro imperio, especialmente mediante el derecho romano. Sin embargo, un tiempo después la primera pasó a control de la comuna de Bolonia, mientras que la segunda colapsó unos años más tarde. Los monarcas de las coronas europeas también trataron de verse beneficiados por las instituciones universitarias. Los reyes de Castilla, de Inglaterra y de Francia esperaban que las universidades fuesen útiles para sus intereses, concretamente las de Salamanca, Cambridge y París. En un primer momento, la universidad de París estuvo principalmente controlada por el papado, luego por la corona inglesa durante la ocupación y, finalmente, cayó en manos de la monarquía francesa. También la universidad de Cahors pasó tiempo bajo influencia de la corona de Inglaterra. Finalmente, se ha encontrado que un poder emergente como las ciudades (Gerona, Mallorca, Barcelona y Lérida en el reino de Aragón, Salamanca en Castilla o Perugia en Italia) ejercieron influencia sobre la universidad con el objetivo de que favoreciese el gobierno y autonomía local y el desarrollo económico como parte del proceso de tránsito del feudalismo a la Edad Moderna. La universidad de Perugia estando bajo control municipal, además, recibió el rango de universidad imperial. Si bien la misión institucional asignada por las élites sociales estaba dirigida hacia el servicio, desde el mismo seno de las universidades se produjeron rupturas. Los casos del wyclifismo y de los goliardos que se han estudiado muestran que hubo colectivos que contestaron el modelo dominante. En estos casos fue precisamente la difusión de ideas reformistas o revolucionarias desde la universidad lo que condujo a la reacción y persecución por parte de las autoridades ortodoxas.

\section{Bibliografía}

Se proporciona el enlace de los libros digitalizados en Internet que están libres de derechos de autor.

(2012) BACA, Vicente, "Modelos de articulación de las funciones sociales de la universidad". En VV.AA., Homenaje al profesor Manuel Núñez Encabo, Departamento de Filosofía del Derecho, Facultad de Derecho de la Universidad Complutense de Madrid, Madrid, (en prensa).

(1970) BELTRÁN DE HEREDIA, Vicente, Cartulario de la Universidad de Salamanca (1218 - 1600), tomo I, Universidad de Salamanca, Salamanca.

(1851) BOFARULL Y MASCARÓ, Próspero, Colección de documentos inéditos del archivo de la Corona de Aragón, tomo VIII, Archivo General de la Corona de Aragón, Barcelona, <http://books.google.com/books?id=vPICz3TUAZsC\&dq=\%22Colecci\%C3\%B3 
n+de+documentos+in\%C3\%A9ditos+del+archivo++de+la+Corona+de+Arag\%C 3\%B3n\%22+\%22Tomo+VIII\%22\&hl=es\&source=gbs_navlinks s> (1986) BRAUDEL, Fernand, La Dinámica del capitalismo, México D.F., Fondo de Cultura Económica.

(1911) BROWN, Wemyss. "University of Perugia", The Catholic Encyclopedia, Vol. 11, Robert Appleton Company, New York, < http://www.newadvent.org/cathen/11737a.htm>

(2010) CANTONI, Davide y YUCHTMAN, Noam, "Medieval Universities, Legal Institutions, and the Commercial Revolution", Berkeley CEnter for Political economy,

California, <http://bcep.haas.berkeley.edu/papers/universitiesdraft_20100608.pdf>

(1994) CLARAMUNT, Salvador, "1450, Barcelona". En Jos M.M Hermans y Marc Nelissen (Eds.), Charters of foundation and early documents of the universities of the Coimbra Group, Leuven University Press, Leuven.

(2010) CERDA, José Manuel, "El Renacimiento europeo del siglo XII", Programa de extensión en humanidades, Universidad Gabriela Mistral, <http://www.edadmedia.cl/docs/12_09/Siglo\%20XII\%20Programa\%20y\%20text os.pdf>

(2010) COMPAYRÉ, Gabriel, Abelard and the Origins and the Early History of Universities, General Books, Memphis, Tennesee, USA.

(2011) CONTI, Alessandro, "John Wyclif", The Stanford Encyclopedia of Philosophy (Winter 2011 Edition), Edward N. Zalta (ed.), $<$ http://plato.stanford.edu/archives/win2011/entries/wyclif/>

(2006) DAVIS, Ralph Henry Charles, A History of Medieval Europe: From Constantine to Saint Louis, Pearson Education, Harlow, UK.

(1920) DEANESLY, Margaret, The Lollard Bible and other medieval Biblical versions, Cambridge University Press, London. $<$ http://www.archive.org/details/lollardbibleothe00deanuoft>

(1889) DENIFLE, Heinrich y CHATELAIN, Emile, Chartularium Universitatis Parisiensis, Tomus I, Ex Typis Fratrum Delalain, Pariis, $<$ http://www.archive.org/details/chartulariumuniv01univuoft>

(2003) FERNÁNDEZ LUZÓN, ANTONIO, La Universidad de Barcelona en el siglo XVI, Tesis Doctoral, Universitat Autònoma de Barcelona, Barcelona, $<$ http://tdx.cat/bitstream/handle/10803/4791/alf1de3.pdf?sequence=1>

(1840) FULLER, Thomas, PROCKETT, Marmaduke y WRIGHT, Thomas, The History of the University of Cambridge from the Conquest to the Year 1634, Cambridge University Press, <http://books.google.es/books?id=fgVMAAAAcAAJ\&dq=The+History+of+the+U niversity+of+Cambridge+from+the+Conquest+to+the+Year+1634\&hl=es\&sourc e=gbs_navlinks_s $>$

(1996a) HALSALL, Paul, "The Great Schism: University of Paris and the Schism", Internet Medieval Sourcebook, Fordham University Center for Medieval Studies, New York, <http://www.fordham.edu/halsall/source/grtschism2.html>

(1996b) HALSALL, Paul, "Statutes of Gregory IX for the University of Paris 1231", Internet Medieval Sourcebook, Fordham University Center for Medieval Studies, New York, <http://www.fordham.edu/halsall/source/UParisstats1231.html> 
(1996c) HALSALL, Paul, "Robert de Courçon: Statutes for the University of Paris", Internet Medieval Sourcebook, Fordham University Center for Medieval Studies, New York, <http://www.fordham.edu/halsall/source/courcon1.asp> (1998) HALSALL, Paul, "Pope Gregory XI: The Condemnation of Wycliffe 1382 and Wycliffe's Reply, 1384", Internet Medieval Sourcebook, Fordham University Center for Medieval Studies, New York, $<$ http://www.fordham.edu/halsall/source/1382wycliffe.asp> (2002) HASKINS, Charles Homer, The Rise of the Universities. Transaction Publishers, New Brunswick, NJ.

(1994) HERNÁNDEZ-VICENTE, Severiano, "1244, Salamanca". En Jos M.M Hermans y Marc Nelissen (Eds.), Charters of foundation and early documents of the universities of the Coimbra Group, Leuven University Press, Leuven.

(s.f) IN REBUS, Inter singular. History of Education. The founding of a Medieval University. Papal Bull concerning the University of Cambridge, <http://www.inrebus.com/cambridgebull.php>

(2008) JANIN, Hunt, The University in Medieval Life. McFarland \& Company, Inc., North Carolina.

(2007) JUSSERAND, Jean Jules, A Literary History of the English People. From the Origins to the Renaissance, Project Gutenberg, Salt Lake City, UT, $<$ http://www.gutenberg.org/files/22049/22049-h/22049-

h.htm\#FNanchor_707_707>

(1996) LE GOFF, Jācques, Los intelectuales en la Edad Media, Gedisa, Barcelona.

(2008) LÓPEZ, Gregorio (Ed.) Las siete partidas del Sabio Rey Don Alonso el IX [sic], Tomo I, Biblioteca Virtual Miguel de Cervantes, Alicante, $<$ http://www.cervantesvirtual.com/obra/las-siete-partidas-del-sabio-rey-donalonso-el-ix-sic-tomo-i-que-contiene-la-1-y-2-partida--0/>

(1977) MARTÍN SERRANO, Manuel, La Mediación social, Akal, Madrid. Reediciones en 1978, 1980, 1982, 1984, 1986 y 2008.

(1996) MARTÍNEZ, Pedro Pascual, "Los goliardos desaparecieron hace siete siglos", Aldaba: revista del Centro Asociado de la UNED de Melilla, $\mathrm{N}^{0} 28$, pp. 459-474, ISSN 0213-7925, Melilla, <http://espacio.uned.es/fez/eserv.php?pid=bibliuned:Aldaba-1996-28-

2300\&dsID=Documento.pdf>

(1897) MUNRO, Diana (Ed.), Translations and reprints from the original sources of European history, Vol. II, No. 3, University of Pennsylvania Press, Philadelphia, <http://www.archive.org/details/translationsrepr02univiala>

(1992) NARDI, Paolo, "Relations with authority". En Hilde de Ridder-Symoens, A history of the university in Europe, Vol. 1, Cambridge Unviersity Press, Cambridge, New York, Port Chester, Melbourne, Sydney, pp. 77-107.

(1908) OGG, Frederic Austin (Ed.). A Source Book of Mediæval History. Documents illustrative of European life and institutions from the German invasions to the Renaissance, American Book Company, New York, Cincinnati, Chicago. <http://www.archive.org/details/sourcebookofmedi00oggfl>

(1983) PIRENNE, Henri, Las ciudades en la Edad Media, Ed. Alianza, Madrid.

(1989) POLANYI, Karl, La gran transformación, La Piqueta, Madrid.

(2005) PONCE, Aníbal, Educación y lucha de clases, Akal, Madrid.

(1863) RILEY, Henry Thomas (Ed.), Thomæ Walsingham, quondam monachi S. Albani, historia anglicana, Ed. Longman, Green, Longman, Roberts, and Green, London, <http://www.archive.org/details/thomaewalsingha00rilegoog> 
(1961) ROBSON, J.A. Wyclif and the Oxford Schools, Cambridge University Press, Cambridge, New York, Melbourne, Madrid, Cape Town, Singapore, São Paulo, Delhi. <http://www.archive.org/details/wyclifoxfordscho00robs>

(1992) RÜEGG, Walter, "Themes". En Hilde de Ridder-Symoens (Ed.), A history of the university in Europe, Volume I: Universities in the Middle Ages, Cambridge Unviersity Press, Cambridge, New York, Port Chester, Melbourne, Sydney, pp. 3-34.

(1992a) SCHWINGES, Rainer Christoph, "Student Education, Student Life". En Hilde de Ridder-Symoens (Ed.), A history of the university in Europe, Volume I, Cambridge Unviersity Press, Cambridge, New York, Port Chester, Melbourne, Sydney, pp. 195-243

(1992b) SCHWINGES, Rainer Christoph, "Admission". En Hilde de RidderSymoens (Ed.), A history of the university in Europe, Volume I, Cambridge Unviersity Press, Cambridge, New York, Port Chester, Melbourne, Sydney, pp. 171-294.

(1998) SPAGNUOLO, Mario, "Lictere Generales, establishing the University of Naples", Internet Medieval Sourcebook, Fordham University Center for Medieval Studies, New York. <http://www.fordham.edu/halsall/source/1224fred2-lictgen.html>

(2007) SYMES, Carol, A common stage: theater and public life in medieval Arras, Cornell University Press, New York.

(1990) TANNER, Norman (Ed.), Decrees of the Ecumenical Councils, Sheed and Ward, London; Georgetown University Press, Washington. D.C., <http://www.ewtn.com/library/councils/florence.htm\#14>

(1905) THATCHER, Oliver y McNEAL, Edgar Holmes (Eds.), A Source Book for Medieval History, Scribners, New York, <http://www.archive.org/details/sourcebookformed00thatiala>

(1907) THATCHER, Oliver (Ed.) The Library of Original Sources, Vol. V: The Early Medieval World, University Research Extension Co., Milwaukee, <http://www.archive.org/details/libraryoriginal00thatgoog>

(1975) THORNDYKE, Lynn (Ed.), University Records and Life in the Middle Ages, Columbia University Press, New York.

(1909) THURSTON, Herbert, "Feast of Fools", The Catholic Encyclopedia, 6, Robert Appleton Company, New York, <http://www.newadvent.org/cathen/06132a.htm>

(s.f) UNIVERSITÀ DEGLI STUDI DI PERUGIA, History of the University. <http://www.unipg.it/comunica/guide/frame1.html>

(1992) VERGER, Jacques, "Teachers". En Hilde de Ridder-Symoens (Ed.), A history of the university in Europe, Volume I, Cambridge Unviersity Press, Cambridge, New York, Port Chester, Melbourne, Sydney, pp. 144- 168.

(1869) VIDAL Y DÍAZ, Antonio, Memoria histórica de la Universidad de Salamanca, Imprenta de Oliva y hermano, Salamanca, $<$ http://www.archive.org/details/memoriahistorica00vidauoft>

(1851) VILLANUEVA, Jaime, Viage literario a las iglesias de España: Viage a Lérida, Volumen 16, ap. N. III, Real Academia de la Historia, Madrid, <http://books.google.es/books/ucm?id=8Q0BwxqTnYAC\&hl=es\&source=gbs_n avlinks_s>

(1908) WALSH, James, The Popes and Science. The History of the Papal Relations to Science During the Middle Ages and Down to Our Own Time, 
Fordham University Press, New York, <http://www.gutenberg.org/files/34019/34019-h/34019-h.htm> (1841) WRIGHT, Thomas (Ed.), The Latin poems commonly attributed to Walter Mapes, Vol. 3. Camden Society, London, $<$ http://books.google.es/books?id=hiAIAAAAIAAJ\&dq=The+Latin+poems+com monly+attributed+to+Walter+Mapes\&hl=es\&source=gbs_navlinks_s>

(1994) ZANNOTI, Andrea, "1088, Bologna". En Jos $\bar{M} . M$ Hermans y Marc Nelissen (Eds.), Charters of foundation and early documents of the universities of the Coimbra Group, Leuven University Press, Leuven. 